\title{
Correlation of Telomere Length and Serotonin Levels with Job Stress and Locus of Control Type among Nurses at a Private Hospital in Gianyar, Indonesia
}

\author{
Susy Purnawati, MD, PhD, MKK, ${ }^{1}$ I Made Krisna Dinata, MD, PhD, MErg, ${ }^{1}$ \\ Ni Made Linawati, MD, PhD, $\mathrm{MSi}^{2}$ and I G Kamasan Nyoman Arijana, MD, MSi ${ }^{2}$ \\ ${ }^{1}$ Physiology Department Medical Faculty, Udayana University \\ ${ }^{2}$ Histology Department Medical Faculty, Udayana University
}

\begin{abstract}
Objectives. Telomere length and its relationship to job stress among workers in the health sector in Indonesia, especially in Bali, have never been studied. The purpose of the study was to analyze the correlation of the telomere length and serotonin levels to job stress and the type of locus of control (LOC) among nurses who were running shift work.

Method. This analytical cross-sectional study was conducted from April to November 2018 among 68 nurses who were running shift work at a private hospital in Gianyar. The telomere length was measured with the absolute telomere length (aTL) using quantitative real-time polymerase chain reaction (qPCR) technique. Locus of control (LOC) was assessed using the IPC-LOC questionnaire. Serotonin level was measured by the immunoassay technique. Job stress was measured using the BJSQ. Data analysis was conducted with Chi-squared test, correlation test, and independent sample t-test.
\end{abstract}

Results. There was a significant correlation of job stress with telomere length $(p=0.03)$. Nurses with job stress faced a 2.9 times risk of short telomere (prevalence ratio, $\mathrm{PR}=2.95,95 \% \mathrm{Cl} 1.02,7.91$ ). The mean telomere length was $17.32 \pm 7.80$ in nurses who experienced job stress vs. $22.45 \pm 8.41$ in nurses who did not experience job stress. Comparing with a previous study done by to O'Callaghan et al., in the young group, the mean aTL was $97.2 \mathrm{~kb} / \mathrm{diploid}$ genome (range 35-260). We also found a significant correlation of job stress score with serotonin level $(p=0.02)$. The serotonin level among nurses with LOC-e type was lower than LOC-i.

Conclusion. There was a significant correlation between job stress and telomere length, where nurses who experienced job stress had a shorter telomere than those who did not experience job stress. There was also a significant correlation between job stress and serotonin levels, where the mean of serotonin levels in nurses with LOC-e type was lower than LOC-i.

Key Words: locus of control, occupational stress, serotonin, telomere shortening

\section{INTRODUCTION}

Corresponding author: Susy Purnawati, MD, PhD, MKK Physiology Department Medical Faculty Udayana University Kampus Bukit, Jl. Raya Kampus Unud Jimbaran Kec. Kuta Sel., Kabupaten Badung, Bali 80361, Indonesia Email: s_purnawati@yahoo.com
Delayed aging is a popular topic in research as well as in scientific discussion in the community. Biomarker findings that become parameters, which reflect the aging process, are increasingly popular and can be quickly applied in the research field. Their application leads to the growth of many studies in the field of occupational health, especially in mental health aspects. They will be very useful in supporting an effort to prevent work-related diseases and to increase productivity.

The prevalence of mental-emotional disorders, such as anxiety and depression, in workers has increased and has 
been reported through several studies in Indonesia and other countries. Job stress by various causes can trigger mechanisms involving the hypothalamo-pituitary-adrenal axis (HPAaxis) and the sympathetic-adreno-medullary axis (SAMaxis). ${ }^{1}$ Activation of both types of axis not only describes the organism's response to stressors, but also physiologically plays a role in normal homeostasis and body metabolism (Lavallo and Thomas, 2000), and is associated with the brain's limbic system activity as the center of emotional control. ${ }^{2}$ This neuro-hormonal pathway explains the mechanism by which job stress can result in the neurotransmitter homeostasis of the brain being affected which affects behavior and cognitive function, as well as causes changes in cellular proteins including DNA structure. This mechanism clarifies the effect of job stress on changes in the body's defense by internal antioxidants against free radicals and is expressed in the telomere profile of DNA. Previous studies found that telomere shortening can be accelerated by environmental factors such as psychological and physiological stress. $^{3-9}$ The telomere length and its relationship to job stress in health workers in Indonesia especially in Bali have never been studied.

Human aging develops from an accumulation of physical, environmental, and social factors. ${ }^{10}$ Many factors, including work factors, influence telomere length. Workplace exposure or, in general, occupational factors, also contribute to telomere shortening and acceleration of the aging process. ${ }^{11}$ Telomeres that have an association with aging and cancer are segments of specific DNA proteins that are the end part of a chromosome. The function of telomeres is to maintain the stability of chromosomes and protect the end of chromosomes or genomes against nucleolytic degradation, un-important or wrong recombination, fused, and interchromosomal attachment. Telomeres are formed by very specific strands and in humans are formed by TTAGG and repetitive DNA protein strands. ${ }^{12}$

Telomere synthesis is catalyzed by the enzyme telomerase. The enzyme also functions to maintain telomeres by forming additional strand structures that lengthen the telomeres and stop the enzyme decomposition process. If the function of the telomerase enzyme is disrupted or when the telomere length reaches a critical limit, there will be senescence and/or apoptosis. Shortening telomeres will result in the shortening of the individual's lifespan due to an increased risk of death from heart disease or cancer. ${ }^{13}$ People who can maintain telomere length have longer lives. ${ }^{12}$ The length of the human telomere is thought to decrease at a speed of 24.8-27.7 base pairs per year. ${ }^{14,15}$ There are no studies that estimate average expected telomere shortening in the exact age range of 20-50 years, which largely falls within the young adulthood period of minimal loss. Therefore, in translating telomere shortening to years of aging, there are estimates in studies averaging telomere shortening across adulthood (ages 20-95 years), which find a loss of 31-63 bp/year. ${ }^{16-18}$ According to O'Callaghan et al., in the young group, the lymphocyte had a mean aTL of $97.2 \mathrm{~kb} /$ diploid genome (range 35-260). ${ }^{19}$

Various factors related to oxidative stress can cause telomere shortening, including chronic stress related to work. ${ }^{20}$ The stress results in the release of glucocorticoid hormones by the adrenal cortex gland. This hormone has been reported to reduce levels of antioxidant proteins ${ }^{21}$, increase oxidative damage to DNA, ${ }^{10}$ and accelerate the shortening of telomeres. ${ }^{22}$ Epel et al. studied women who experienced stress in daily life, proving that there was an increase in oxidative pressure, decreased telomere activity, and shortening of telomeres in peripheral blood mononuclear cells. ${ }^{23}$ According to Cawthon et al., individuals with short telomeres have significantly poor survival due to high mortality due to heart disease and infections. ${ }^{13}$ The mean length of leukocyte telomeres in patients with coronary heart disease (CHD) (adjusted for age and sex) is approximately 300 base pairs shorter than healthy subjects. ${ }^{24}$ Hoxha et al. examined the telomere length of leukocytes in office workers and traffic police officers who were exposed to traffic pollution, and found that the telomere length of traffic police officers was shorter relative to the telomere length of office workers. It was also found that there was a positive relationship between telomere length and the working period of workers exposed to environmental exposures in their workplaces. ${ }^{25}$ The shortening of telomeres in worker lymphocytes in the study was related to hypomethylation of $\mathrm{p} 53$ promoter (Pavanello et al., 2010 in Shammas), ${ }^{26}$ which induced p53 expression (Esteller in Shammas, 2011), which led to apoptosis. ${ }^{27}$

Besides an effect on shortening telomeres, job stress can also reduce blood serotonin levels and stimulate an imbalance in the ratio of neurotransmitter dopamine vs serotonin in the blood and is reflected in the mood. Generally, individuals will react to the discomfort that arises from any stress in the form of behavior, cognitive (or mind), and emotions or mood. This reaction could appear as a coping mechanism. The coping mechanism of stress serves as a stabilizer that helps people to maintain psychosocial adjustments during the stress period. If the response is successful, the person will not suffer physical illness and mental-emotional disorders. Conversely, if the stress management mechanism does not work, then the individual will suffer from the disease as a process of maladaptation to stress. The maladaptation process occurs because the function of maintaining homeostasis by cortisol and other mediators no longer plays a physiological role. One marker of the process of maladaptation is illustrated by a decrease in blood serotonin levels. Body chemicals known as $\beta$-endorphins that are morphine-like and similar compounds are secreted with ACTH after being stimulated by $\mathrm{CRH}$ during stress. It is thought that $\beta$-endorphins, as strong endogenous opiates, may play a role in causing analgesia (decreased pain perception) in the event of physical injury due to stress. Furthermore, it is also speculated that the peptides are released to play a role in the learning process and mood swings. Mental stress can cause an increase in 
ACTH secretion. This condition is considered as a result of increased activity in the limbic system, especially in the amygdala and hippocampal regions, both of which then carry signals to the medial posterior part of the hypothalamus. It is reasonable that a prolonged stress condition will disrupt the blood serotonin homeostasis system. In theory, low serotonin results in cognitive impairment and changes in mood and behavior and is associated with many other health problems such as decreased immunity and inflammatory responses with all the consequences. ${ }^{28}$ Job stress can reduce serotonin level, which is associated with lower mood and have an impact on behavior. People with low serotonin levels tend to have anxious behavior and are at risk for depression. This can reduce work productivity.

A personality attribute, that is, the locus of control (LOC) type of worker is also associated with conditions of job stress or risk of depression..$^{29,30}$ LOC is the ability to control the individual self and is related to the perspective or mindset of individuals about success and failure, ${ }^{31}$ where this ability will cause perceptions or orientation to individuals when experiencing events in life. This perception or orientation greatly influences the level of motivation, expectations, self-esteem, risk-taking behavior, decision-making and ultimately will influence the actual results resulting from one's actions as a circle of cause and effect. This perception or orientation is called locus of control (LOC). ${ }^{32}$

LOC is divided into two types, namely internal type LOC (LOC-i) and external type LOC (LOC-e). Individuals with LOC-i believe that they have control over what happens in their lives and understand that the results obtained depend on how much effort is done, ${ }^{32}$ whereas individuals with LOC-e will view that everything that happens in his life is caused by factors outside themselves, such as chance, luck, destiny, or the actions of others in power. ${ }^{33}$ LOC has been associated with onset, course, and severity of anxiety and depression. ${ }^{34}$ Persons with LOC-i tend to feel happier, are rarely stressed, and are patient and optimistic. Persons with LOC-e are more prone to depression and various health problems. Individuals who have LOC-i believe that their destiny is under their control, whereas individuals with LOC-e believe that their destinies are controlled by forces outside themselves. Individuals who have an internal locus of control experience less threat than those who are externally oriented. The reaction to the stress generator is different for the internal and external oriented. Internally, there is a tendency to seek information and solve problems, whereas external parties react more with helplessness. Everyone has an internal and external LOC with different qualities. This shows that the more dominant the internal type LOC, the lower the external type LOC is and does not rule out the possibility that there are individuals who have it in the same quality. In theory, it is said that individuals with greater external LOC tend to experience job stress and are at risk for mental disorders. ${ }^{32-34}$
Correlation between LOC and job stress can be explained by COR theory ${ }^{35,36}$ and the Job DemandsResources (JD-R) model. ${ }^{37}$ The conservation of resources (COR) theory asserts that an individual aspires to preserve, protect, and build resources. Resources are characterized as objects, conditions, personal characteristics, or energies that have specific importance for the individual. According to Hobfoll, ${ }^{36}$ the COR theory states that the prime human motivation is directed towards the maintenance and accumulation of resources. Accordingly, resources are valued in their own right or because they are means to achieve or protect other valued resources. Job resources may be located at the macro, organizational level (e.g., salary or wages, career opportunities, job security), the interpersonal level (e.g., supervisor and coworker support, team climate), the specific job position (e.g., role clarity, participation in decision making), and at the level of the task (e.g., skill variety, task identity, task significance, autonomy, and performance feedback). According to the COR theory, stress occurs when individuals are threatened with resource loss. The inability to replenish energy resources may lead to long-term fatigue, which hampers normal functioning in many aspects of daily life, including work. ${ }^{36}$ The JD-R model explains that every occupation has its specific risk factors associated with job-related stress. These factors can be classified into two general categories (i.e., job demands and job resources). Job demands refer to physical, psychological, social, or organizational aspects of the job that require sustained physical and/or psychological (cognitive and emotional) effort or skills and are therefore associated with certain physiological and/or psychological costs. Examples include high work pressure, an unfavorable physical environment, and irregular working hours. Although job demands are not necessarily negative, they may turn into job stressors when meeting those demands require high effort from which the employee fails to recover adequately. Job resources refer to physical, psychological, social, or organizational aspects of the job that are either/or: 1) functional in achieving work goals; 2) reduce job demands and the associated physiological and psychological costs; 3) stimulate personal growth, learning, and development. ${ }^{38}$

The main hypothesis of this study was: there is a correlation between the telomere profile and the work stress of nurses at a private hospital in Bali. Secondary hypotheses were: 1) There is a correlation between serotonin levels and job stress, and 2) There is a correlation between the type of locus of control to serotonin levels.

\section{METHOD}

\section{Study population}

We randomly selected volunteers from the total population of nurses in a private hospital at Ubud-BaliIndonesia using a simple random sampling technique in 2018. The inclusion criteria were: nurses who conducted 
shift work, aged 19-45 years, and with normal body mass index (BMI). The exclusion criteria were: nurses in the premenstrual period, with signs of anxiety requiring medication, or suffering from a disease diagnosed by a doctor.

\section{Outcome Measures}

\section{Telomere and Serotonin levels}

Serotonin was measured using the Immunoassay technique; while the length of telomere was measured by absolute telomere length (aTL) using quantitative real-time polymerase chain reaction (qPCR) conducted at the Mantra Clinic Lab. The measurement of aTL was performed in the lymphocyte cell population from which was collected high quality undamaged cells. This method was based on the Cawthon method for relative measurement of telomere length (TL) but modified by introducing an oligomer standard to measure aTL. The advantage of the qPCR method is only small amounts of DNA are required and easily be performed in high-throughput format. ${ }^{39}$

\section{Job stress (A Self-report questionnaire)}

Job stress was measured using the Indonesian version of the Brief Job Stress Questionnaire (BJSQ). ${ }^{40-41}$ The job stress variable in the form of numerical data was analyzed as a total or overall score from all items of the BJSQ (=job stress score). The subscales of the questionnaire include job stressors (job demand and job control), psychological distress, physical stress reaction (or complaint), social support, and concerning satisfaction.

Since there was no cutoff point of the overall BJSQ score, we also analyzed the job stress variable by the job strain index (JSI) to be able to do the Chi-squared test for categorical data, as well as LOC data, and look for the prevalence ratio of the short telomere risk caused by job stress. The job strain index (JSI) is the subscale of BJSQ which contains job demand and job control. According to the job strain model/theory, job demands depend on individual workload needed to carry out and the time limitation related to it, and job control is related to work process control, which means the ability to make decisions and having the time to implement control measures over the work to accomplish it. The calculation of JSI was done by dividing the score of job demands (7 items) by job control ( 3 items) quoted from BJSQ. ${ }^{40} \mathrm{~A}$ mean JSI $>1$ indicates that employees experience job stress. ${ }^{40} \mathrm{~A}$ high score is thus representative of severe job demands with little control over the work situation. The BJSQ uses a 4-point Likert scale, ranging from 1 (agree) to 4 (disagree).

\section{Type of the Locus of Control (LOC) (Self-report questionnaire)}

LOC was assessed using the IPC-LOC questionnaire developed by Rotter. By distinguishing internal-external factors into three factors, namely: internality (I), powerful others $(\mathrm{P})$, chance $(\mathrm{C})$, referred to as the IPC scale. The factor
I describe internal type LOC (LOC-i), while factors $\mathrm{P}$ and $\mathrm{C}$ describe external type LOC (LOC-e). Munandar found that the IPC scale had a high internal consistency among factors I, P, and C. Participants were only allowed to choose one of the six possible answers for each statement item. The possible answers are "strongly agree" (SS) with a score of 6 , agree (S) with a score of 5 , agree somewhat (AS) with a score of 4 , somewhat disagree (ATS) with a score of 3, disagree (TS) with a score of 2 , and strongly disagree (STS) with a score of 1. A higher score on factor I means a tendency for higher internality (internalized), whereas a higher score on factors $\mathrm{P}$ and $\mathrm{C}$ is interpreted to have a high tendency for externalities (externalized). This IPC scale had a Cronbach $\alpha=0.971 .{ }^{42}$

\section{Potential confounders}

We controlled by design for potential confounders, i.e., age and length of employment. Other factors related to stress among nurses, as well as sleep disturbance and stress due to financial problem were evaluated and analyzed by frequency distribution. These variables were assessed using a selfanswered checklist (yes or no question).

\section{Data analysis}

To test the hypotheses, we analyzed the two sets of categorical data by chi-squared test as well as numerical data by correlation test. The difference in scores on the measures between the two datasets was analyzed with the independent t-test, which was previously checked for normality by the Kolmogorov Smirnov test.

\section{Ethics statement}

This study was approved by the medical research/ethics review board of the Medical Faculty of Udayana University/ Sanglah Hospital Denpasar.

\section{RESULTS}

We randomly selected 70 nurses from a total population of 198. Two participants were not present at the time of data collection, so data analysis was carried out on 68 participants. There were 11 men (16.2\%) and 57 women (83.8\%), with an average age of 27.3 years (range, 23 to 44 ). The mean length of employment was 4.8 years.

Among 68 nurses, there was a high proportion (32 or $47 \%$ ) of those who were experiencing job stress (JSI score $>1$ ). The remaining 36 had a JSI score $<1$. Sleep disturbance was reported by 20 participants (29.4\%). The peak stress day was on Monday (42 or 62\%). Factors that caused the stress were financial conditions $(52,77 \%)$, travel to the workplace (31 or $46 \%$ ), side job activities (28 or $41 \%$ ), family factors (14 or 20.6\%), and religious activities (2 or 3\%), Participants who exercised frequently numbered 23 (34\%); only one participant (2\%) frequently did activities to reduce stress.

The mean telomere length among nurses was 22.264 and the mean psychological distress score was 38.3 (Table 1). 
Table 1. Descriptive statistics for the key study variables

\begin{tabular}{lcccc}
\multicolumn{1}{c}{$\quad(\mathrm{N}=68)$} & & & & \\
\multicolumn{1}{c}{ Variable } & Mean & SD & Minimum & Maximum \\
\hline Age (year) & 27.3 & 3.80 & 23.0 & 44.0 \\
Length of employment & 4.8 & 3.25 & 0.8 & 16.0 \\
(year) & & & & \\
Telomere & 22.264 & 15.791 & 4.804 & 95.946 \\
Job strain index & 1.007 & 0.221 & 0.430 & 1.5 \\
Psychological distress & 38.3 & 7.037 & 23.0 & 60.0 \\
Physical complaint & 20.46 & 5.156 & 11.0 & 33.0 \\
Concerning satisfaction & 3.12 & 0.879 & 2.0 & 5.0 \\
\hline
\end{tabular}

Table 2. Crosstab of LOC by JSI category

\begin{tabular}{llccc}
\multirow{2}{*}{ Variable } & \multicolumn{2}{c}{ JSI Category } & \multirow{2}{*}{ Total } \\
\cline { 3 - 4 } & & JSI $<1$ & JSI $>1$ & \\
\multirow{2}{*}{ LOC Category } & Internalized & 3 & 6 & 9 \\
& Externalized & 33 & 26 & 59 \\
\hline Total & 36 & 32 & 68 \\
\hline
\end{tabular}

JSI, Job strain index

Table 3. Crosstabulation of telomere and job strain index

\begin{tabular}{|c|c|c|c|c|}
\hline \multirow{2}{*}{\multicolumn{2}{|c|}{ Variable }} & \multicolumn{2}{|c|}{ Job stress } & \multirow{2}{*}{ Total } \\
\hline & & No $(J S I \leq 1)$ & Yes (JSI > 1) & \\
\hline \multirow[t]{2}{*}{ Telomere } & Long & 23 & 12 & 35 \\
\hline & Short & 13 & 20 & 33 \\
\hline Total & & 36 & 32 & 68 \\
\hline
\end{tabular}

JSI, Job strain index

People with an external locus of control tended to get stressed more easily and were prone to mood disturbances comparing with internal type. This variable was also important in the job stress model. Nurses who had job strain index (JSI) scores >1 were dominant (81.3\%) in nurses with LOC-e (Table 2). This means job stress was dominant among nurses with an external type of locus of control.

The normality test of serotonin level and telomere length data was performed using the Kolmogorov Smirnov test with $\mathrm{p}$-value $=0.001$, which means the data was not normally distributed. The serotonin data homogeneity test using the Levene test got a $p$-value $=0.269$, which means the data was homogeneous.

Univariate analysis of telomere length (categorical data) with job strain index in cross-tabulation (Table 3 ) shows that 20 nurses with job stress $(\mathrm{JSI}>1)$ have short telomere. To find the risk of short telomere in correlation with job stress, we also did statistical analysis using the chi-squared test (Table 4), where the telomere variable was dichotomized as short and long telomere to find the prevalence ratio. The job stress variable in this statistical analysis used JSI. We found the prevalence ratio $(\mathrm{PR})$ to be 2.949 , which means that there was 2.9 times short telomere risk among nurses who suffered job stress.
Table 4. Correlation of JSI to telomere length

\begin{tabular}{|c|c|c|c|c|c|c|}
\hline \multirow{2}{*}{ JSI } & \multirow{2}{*}{$\mathrm{n}$} & \multicolumn{2}{|c|}{ Telomere Length } & \multicolumn{2}{|c|}{$95 \% \mathrm{Cl}$} & \multirow[b]{2}{*}{ p } \\
\hline & & Mean & SD & Lower & Upper & \\
\hline JSI low $(\leq 1)$ & 36 & 22.448 & 8.409 & 1.019 & 7.914 & \\
\hline JSI high (>1) & 32 & 17.322 & 7.796 & & & 0.030 \\
\hline
\end{tabular}

JSI, Job strain index

Table 5. Correlation between job stress and serotonin level

\begin{tabular}{lccc}
\multicolumn{1}{c}{ Variable } & Mean & SD & p \\
Score of job stress & 113.320 & 11.584 & 0.023 \\
Serotonin level $(\mathrm{ng} / \mathrm{ml})$ & 179.303 & 177.783 & \\
\hline
\end{tabular}

Table 6. Mean differences in serotonin levels among types of LOC

\begin{tabular}{lcccccc}
\multirow{2}{*}{ Variable } & \multicolumn{2}{c}{ LOC-i $(\mathbf{n}=9)$} & & \multicolumn{2}{c}{ LOC-e $(\mathbf{n}=59)$} & \\
\cline { 2 - 3 } & Mean & SD & & Mean & SD & \\
\hline $\begin{array}{l}\text { Serotonin } \\
(\mathrm{ng} / \mathrm{ml})\end{array}$ & 201.2878 & 188.506 & & 170.7632 & 179.766 & 0.658 \\
\hline
\end{tabular}

Note: Independent sample t-test; LOC-i, Locus of control-internalized; LOC-e, Locus of control-externalized

The mean telomere length was shorter among nurses that suffered job stress (17.322) (Table 4). Compared with the previous study by O'Callaghan et al., lymphocytes in the young group had a mean aTL of $97.2 \mathrm{~kb} /$ diploid genome (range $35-260.)^{19}$

To do a bivariate analysis of serotonin as numerical data, we calculated the overall score of the job stress scale including job strain, psychological distress, physical complaints, and concerning satisfaction, and analyzed its correlation with blood serotonin. There was a significant correlation between job stress score and serotonin with $\mathrm{p}<0.05$ (Table 5).

Nurses with internal type locus of control type have higher serotonin levels compared to nurses with external type locus of control type (Table 6), however this was not significant $(\mathrm{p}=0.66)$. It means that no significant correlation was found between differences in LOC type and blood serotonin levels.

\section{DISCUSSION}

The main finding in this study is that there was a significant correlation between job stress and the length of telomeres among nurses of a private hospital $(\mathrm{p}=0.03)$. Nurses with job stress have a risk of 2.949 times having shorter telomeres than those without job stress (95\% CI $1.019,7.914)$. Our result is in line with a study by Epel et al. (2004) among 58 healthy premenopausal women who were caregiving their children. They found that the high-stress group had significantly shorter telomeres (raw mean T/S ratio $=1.13 \pm 0.17$ ), which converts to 3,110 -bp telomeres, than the low-stress group (raw mean T/S ratio $=1.33 \pm 0.15$ ). The study also indicated that the 550-bp shortening in the 
high-stress group meant that their lymphocytes had aged the equivalent of 9-17 additional years, compared with the low-stress group.

Referring to the JD-R theory, high job stress scores indicate that job demands are not per the capacity of employees and the rewards they receive. ${ }^{37} \mathrm{~A}$ large number of patients with bad physical conditions or diseases are the responsibility of nurses during their duty at the hospital. This condition is demanding and requires full concentration and has high stress. They suffer from chronic job stress and have a risk for telomere shortening. The acceleration of cellular aging described by shortening telomeres has been reported as one of the mechanisms linking chronic stress with its effects on poor health. ${ }^{23}$ As previously explained, telomeres are DNAprotein complexes that function as biological markers of cell age. ${ }^{43}$ The mechanism can be explained as follows. When the cell divides, telomeres are not fully replicated because of the limitations of DNA polymerase in completing the replication of the end of the linear molecule, which causes telomere shortening with each replication. After enough shortening, the cells start aging. According to previous studies, leukocyte telomeres are shorter in the elderly, smokers, obese individuals, people with low education, and those who experience stress. ${ }^{4}$ In his study, in 58 otherwise healthy mothers, perceived stress was related to the length of their leukocyte telomeres, which was shown to be linearly shortened as a result of the many years spent caring for seriously ill children.

The relative leukocyte telomere length ( $\mathrm{T} / \mathrm{S}$ ratio) (another method of measuring telomere length besides aTL) was an average of 1,104 ( $\mathrm{SD}=0.005)$. Age is positively related to relative telomere length. In addition, sex and body mass index are also related to relative telomere length. A man with a higher body mass index is associated with shorter telomeres. The length of the telomere is not related to marital status, level of work, smoking, or having a physical illness or general mental disorders. It has also been proven that there is a long telomere relationship associated with work-related fatigue. Those who have fatigue due to severe work have shorter telomeres than those who have mild or no fatigue. The difference in telomere length is at an average of 0.043 relative units between individuals with severe fatigue and those who are not fatigue and 0.002 units relative between those with mild fatigue and those who are not fatigued. In the study, the relationship between work-related fatigue and telomere length remained relatively statistically significant after adjusting for marital status, work rates, daily smoking, body mass index, physical illness, and generally mental disorders. After adjustment, the difference was 0.044 relative units between those with severe fatigue and those without fatigue and 0.003 between those with mild fatigue and those without fatigue. ${ }^{4}$ As with other agent factors, stress factors studied in female workers are said to contribute to a shortening of age to the equivalent of 10 years of their proper age. Obesity reduces about the equivalent of 8.8 years of age for telomere shortening that occurs. ${ }^{4}$
Chronic job stress is believed to affect health through the mechanism of "the wear and tear of the organism." ${ }^{44}$ Shortening of telomeres has been reported as part of a general stress response in a variety of situations that are chronically perceived to be demands for individuals. ${ }^{43,45}$ This supports the idea that part of the 'hearing' in situations of work stress might be caused by accelerated cellular aging. Hoxha et al examined the telomere length of leukocytes in office workers and traffic police officers who were exposed to traffic pollution and found that the telomere length of traffic police officers was shorter, relative to the telomere length of office workers.

In this study, we found a significant relationship between job stress scores and blood serotonin levels. The higher the stress score, the lower the serotonin level. Job stress due to various causes can reduce serotonin, which is related to lower mood and has an impact on behavior. ${ }^{46}$ Serotonin is a neurotransmitter formed by tryptophan. McKrittick et al., in their animal studies, found that experiencing chronic stress causes a decrease in the number of branch points and the total dendritic length in the apical dendritic trees of the pyramidal neuron CA3 in the stressed group compared to controls; it also has a reduced number of dendritic branch points. ${ }^{47}$ Through this mechanism, job stress affects brain neurotransmitter homeostasis, which results in low serotonin levels and an impact on behavior and cognition. Job stress has an impact on depressed mood due to its effect on gene polymorphisms of the serotonin transporter (5HTT). Prolonged job stress can result in low serotonin. Job stress may elicit biological responses that contribute to depressed mood in relation to $5 \mathrm{HTT}$ polymorphisms. ${ }^{48} \mathrm{Karg}$ et al., in a meta-analysis, found from 55 follow-up (longitudinal) studies that 5-HTTLPR (serotonin transporter gene) is a moderating factor in the relationship between stress and depression which gives a person sensitivity to stress. ${ }^{49}$ Mental stress can cause an increase in ACTH secretion. This condition is considered as a result of increased activity in the limbic system, especially in the amygdala and hippocampal regions, both of which then carry signals to the medial posterior part of the hypothalamus. It is reasonable that a prolonged stress condition will disrupt the blood serotonin homeostasis system, although there are genetic factors and several other factors that can also affect a person's serotonin levels. Gene polymorphisms are associated with low levels of serotonin which are hereditary.

A study by Serebruany et al. found serotonin levels in the range of $594 \pm 288 \mathrm{ng} / \mathrm{ml}$ in depressed individuals and in normal (control) people in the range of $780 \pm 253 \mathrm{ng} / \mathrm{ml}$. This study found a lower mean blood serotonin level (179.303 \pm 177.783 ) than their study. ${ }^{50}$ The possibility of differences in the intake of each individual between the two studies can be a differentiating factor. These conditions can be an opportunity for further studies relating to efforts to increase workers' serotonin levels. Improved intake (as a source of L-tryptophan) in addition to improving working conditions which are balanced by improving the coping mechanism 
of workers can be a priority in increasing worker serotonin. According to Field et al., massage therapy can increase serotonin levels by $28 \% .^{51}$

In this study, we found a higher mean serotonin level in respondents with LOC-i $(201.2878 \mathrm{ng} / \mathrm{ml})$, than those with LOC-e $(170.7632 \mathrm{ng} / \mathrm{ml})$, but this difference was not statistically significant. Theoretically, the type of locus of control of workers is also associated with conditions of job stress or risk of depression. ${ }^{29,30}$ The small sample size in this study can be the reason for the unanswered second hypothesis. In addition, environmental factors can influence serotonin levels and the formation of LOC types also plays a role in the sensitivity of individuals to experience stress. Another factor that may cause this was that confounding factors such as the habitual nutrient intake between the two types of LOC were not examined so that there is a possibility of confounding in the form of differences in the intake of serotonin-forming material derived from L-tryptophan. Another factor is not identifying the ability or availability of serotonin receptors that affect serotonin uptake in cells, which in turn will play a role in influencing the behavior or type of LOC. It seems there is the involvement of genetic factors in individual sensitivity to stress related to behavior, serotonin levels, and serotonin uptake in influencing their behavior. ${ }^{52}$

\section{Limitation and suggestion for future research}

For future research, a bigger sample size is needed from various work sectors involved as study participants aimed at obtaining the length of telomere characteristics from workers in various health hazards. In addition, this study has some limitations; first, the use of self-report survey data in this study may be biased due to Balinese or Indonesian workers having concerns over the statements or answers they provide for research will have an impact on the possibility of sanctions being dropped by the company or allegedly affected their payment from the company. Second, this study does not measure telomerase enzyme activity. Moreover, this study uses a cross-sectional design, and other factor-related stress could potentially be confounding variables, such as the economic problem, sleep disturbance, autoimmune diseases, and some lifestyle conditions (e.g., exercise habit). Third, future research is needed to prove the relationship between telomere length and job stress. Longitudinal study designs and studies that measure serotonin uptake as a description of serotonin receptor function should further explore the relationship between serotonin variables and work stress and involve larger samples and other professions (e.g., surgeons), which have a higher risk and long work hours.

\section{CONCLUSION}

There is a significant correlation between job stress and the telomere profile of nurses who run shift work, where nurses who experience job stress have a shorter telomere than those who do not experience job stress. There was also a significant relationship between job stress and serotonin levels, where the mean serotonin level in nurses with LOC-e type was lower than LOC-i.

\section{Statement of Authorship}

All authors participated in the data collection and analysis and approved the final version submitted.

\section{Author Disclosure}

All authors decalared no conflicts of interest.

\section{Funding Source}

This study was funded by the PNBP (Institution) Research Grants of Udayana University

\section{REFERENCES}

1. Appels A, Kop WJ. Fatigue \& Stress. In: Appels A, Kop WJ, eds. Encyclopedia of Stress. 2nd Ed. USA: Elsevier Inc; 2007. pp. 11-14

2. Sonnentag S, Fritz C. Endocrinological processes associated with job stress: Catecholamine and cortisol responses to acute and chronic stressors. In: Perrewé PL \& Ganster DC, eds. Research in occupational stress and well-being. Elsevier Science/JAI Press; 2006. pp. 1-59. https://doi.org/10.1016/S1479-3555(05)05001-8

3. Bull CF, O'Callaghan NJ, Mayrhofer G, Fenech MF. Telomere length in lymphocytes of older South Australian men may be inversely associated with plasma homocysteine. Rejuvenation Res. 2009; 12(5):34-9. doi: 10.1089/rej.2009.0868.

4. Epel ES, Blackburn EH, Lin J, Dhabhar FS, Adler NE, Morrow JD, Cawthon RM. Accelerated telomere shortening in response to life stress. Proceedings of the National Academy of Sciences of the United States of America. 2004; 101(49):17312-5. doi: 10.1073/ pnas.0407162101.

5. Morla M, Busquets X, Pons J, Sauleda J, MacNee W, Agusti AG. Telomere shortening in smokers with and without COPD. Eur Respir J. 2006;27(3):525-8. doi: 10.1183/09031936.06.00087005.

6. Paul L, Cattaneo M, D'Angelo A, Sampietro F, Fermo I, Razzari C, Fontana G, Eugene N, Jacques PF, Selhub J. Telomere length in peripheral blood mononuclear cells is associated with folate status in men. J Nutr. 2009; 139(7):1273-8. doi: 10.3945/jn.109.104984.

7. von Zglinicki T. Oxidative stress shortens telomeres. Trends Biochem Sci. 2002; 27(7):339-44. doi: 10.1016/S0968-0004(02)02110-2.

8. Zannolli R, Mohn A, Buoni S, Pietrobelli A, Messina M, Chiarelli F, Miracco C. Telomere length and obesity. Acta Paediatr. 2008; 97(7):952-4. doi: 10.1111/j.1651-2227.2008.00783.x.

9. Richards JB, Valdes AM, Gardner JP, Kato BS, Siva A, Kimura M, Lu X, Brown MJ, Aviv A, Spector TD. Homocysteine levels and leukocyte telomere length. Atherosclerosis. 2008; 200(2):271-7. doi:10.1016/j.atherosclerosis.2007.12.035.

10. Davalli P, Mitic T, Caporali A, Lauriola A and D'Arca D. ROS, Cell Senescence, and Novel Molecular Mechanisms in Aging and Age-Related Diseases. Oxid Med Cell Longev. 2016:3565127. doi: 10.1155/2016/3565127

11. Kahl VFS \& da Silva J. Telomere Length and Its Relation to Human Health. In: Larramendy ML, eds. Biochemistry, Genetics and Molecular Biology. 2016. pp. 163-6. Available from: https://www. intechopen.com/books/telomere-a-complex-end-of-a-chromosome/ telomere-length-and-its-relation-to-human-health

12. Tosato M, Zamboni V, Ferrini A, and Cesari M. The aging process and potential interventions to extend life expectancy. Clin Interv Aging. 2007; 2(3):401-12.

13. Cawthon RM, Smith KR, O’Brien E, Sivatchenko A, Kerber RA. Assossiation between telomere length in blood and mortality in people aged 60 years or older. Lancet. 2003 Feb 1; 361:393-5. 
14. Valdes AM, Andrew T, Gardner JP, Kimura M, Oelsner E. Cigarette smoking, and telomere length in women. Lancet. 2005; 366:662-4.

15. Brouilette S, Singh RK, Thompson JR, Alison HG and Nilesh JS. White cell telomere length and risk of premature myocardial infarction. Arterioscler Thromb Vasc Biol. 2003; 23(5):842-6.

16. Iwama H, Ohyashiki K, Ohyashiki JH, Hayashi S, Yahata N, Ando $\mathrm{K}$, et al. Telomeric length and telomerase activity vary with age in peripheral blood cells obtained from normal individuals. Hum Genet. 1998; 102(4):397-402.

17. Hastie ND, Dempster M, Dunlop MG, Thompson AM, Green DK, Allshire RC. Nature. 1990; 346( 6287):866-8.

18. Satoh H, Hiyama K, Takeda M, Awaya Y, Watanabe K, Ihara Y et al. Telomere shortening in peripheral blood cells was related with aging but not with white blood cell count. Jpn J Hum Genet. 1996; 41(4):413-7.

19. O'Callaghan and Michael Fenech M. A quantitative PCR method for measuring absolute telomere length. Biol Proced Online. 2011; 13(3):1-10. doi: 10.1186/1480-9222-13-3

20. Purwaningsih E. Telomere shorten and apoptosis. Jurnal Kedokteran Yarsi. 2014; 22(2):132-41.

21. Patel MN. Oxidative stress, mitochondrial dysfunction, and epilepsy. Free Radic Res. 2002 Nov; 36(11):1139-46.

22. Von Zglinicki T. Oxidative stress shortens telomeres. Trends Biochem Sci. 2002 Jul; 27(7):339-44

23. Epel E, Blackburn EH, Lin J, Dhabhar FS, Adler NE, Morrow JD, et al. Accelerated telomere shortening in response to life stress. PNAS. 2004; 101:17312-5.

24. Serrano AL, Andres V. Telomeres and cardiovascular disease: does size matter? Circ Res. 2004; 94(5):575-84

25. Hoxha M, Dioni L, Bonzini M, Pesatori AC, Fustinoni S, Cavallo $\mathrm{D}$, et al. Association between leukocyte telomere shortening and exposure to traffic pollution: a cross-sectional study on traffic officers and indoor office workers. Environ Health. 2009; 8(41):1-9.

26. Shammas MA. Telomeres, lifestyle, cancer, and aging. Curr Opin Clin Nutr Metab Care 2011; 14(1):28-34.

27. Chin L, Tam A, Pomerantz J, Wong M, Holash J, Bardeesy N, et al. Essential role for oncogenic Ras in tumor maintenance. Nature. 1999 Jul; 400(6743):468-72.

28. Hansson AS., Vingard E., Arnetz BB, Andersen I. Organizational change, health, and sick leave among health care employees: a longitudinal study measuring stress markers, individual, and worksite factors. Work \& Stress. 2008 Jan; 22(1):69-80.

29. Heath RL, Saliba M, Mahmassani O, Major SC, Khoury BA. Locus of control moderates the relationship between headache pain and depression. J Headache Pain 2008; 9(5): 301-308.

30. Cohen E, Sade M, Benarroch F, Pollak Y, Gross-Tsur V. Locus of control, perceived parenting style, and symptoms of anxiety and depression in children with Tourette's syndrome. Eur Child Adolesc Psychiatry. 2008; 17(5):299-305.

31. Iswara, N.P.A.A., Mahayati, L. N. A., Dewi, N.M. R. P. Correlation of Depression and LOC among Medical School Students. In Rustina C, Purnawati S. Correlation of Depression and LOC among meditation club members at Denpasar City. Jurnal Medika Udayana. 2015; 4(8): $1-13$

32. Asthiningsih, N. W. W., Marchira, C. R., Sedyowinarso, M. Correlation of self-control and depression among students of Program B Undergraduate School of Nurse Medical Faculty UGM. Berita Kedokteran Masyarakat. 2010 Sept; 26(3):38-143.

33. Jaya E, Danta G, Rahmat I. Burnout, reflection from internal and external Locus of Control. 2005. Majalah Kedokteran Nusantara. 2005 Sept; 38(3):213-8.

34. Hovenkamp-Hermelink JHM, Jeronimus BF, van der Veen DC, Spinhoven P, Brenda W J H Penninx BWJH, Robert A Schoevers RA, et al. Differential associations of locus of control with anxiety, depression and life-events: a five-wave, nine-year study to test stability and change. J Affect Disord. 2019 Jun; 253:26-34. DOI: 10.1016/j.jad.2019.04.005.
35. Hobfoll SE. Conservation of resources. A new attempt at conceptualizing stress. Am Psychol. 1986; 44(3):513-24.

36. Hobfoll, S. E. (2001). The influence of culture, community, and the nested-self in the stress process: Advancing conservation of resources theory. Applied Psychology: An International Review. 2001; 50(3), 337-421. doi: 10.1111/1464-0597.00062

37. Bakker AB, Demerouti E. The Job Demands-Resources model: State of the art. Journal of Managerial Psychology. 2007; 22(3):309-28.

38. Demerouti E, Bakker AB. The Job Demands- Resources model: Challenges for future research. SA j. ind. Psychol. 2011; 37(2):1-9. DOI:10.4102/ sajip.v37i2.974

39. O'Callaghan N, Dhillon V, Thomas P, Fenech M. A quantitative real-time $\mathrm{PCR}$ method for absolute telomere length. Biotechniques. 2008;44(6):807-9.

40. Shimomitsu T, Haratani T, Nakamura K, Kawakami N, Hayashi T, Hiro H, et al. Final development of the Brief Job Stress Questionnaire mainly used for assessment of the individuals. In: The Ministry of Labor sponsored grant for the prevention of work-related illness, FY 1999 report, Kato M (Ed.). 2000. pp. 126-64, Tokyo Medical University, Tokyo. In: Kawakami, N. Assessment of Job Stress, Lecture Material. 2010. Tokyo Medical University, Tokyo.

41. Susy-Purnawati. Application of Ergo-JSI decreases job stress among a private bank worker in Denpasar. (Doctoral thesis). 2012. Postgraduate Study Program of Udayana University.

42. Setyorini TD. Effect of attitudes towards the traditional nontraditional role of women and Locus of Control on achievement motivation in Javanese women, Chinese and Arabic ethnic Batik Traders in the Klewer Market in Surakarta. (Magister thesis). 2002. Jakarta: Postgraduate Program of Faculty of Psychology, University of Indonesia.

43. Chan SR, Blackburn EH. Telomeres and telomerase. Philos. Trans. R. Soc. London B 359. 2004. pp. 109-21.

44. Kivima"ki M, Virtanen M, Elovainio M, Kouvonen A, Vaananen A, Jussi Vahtera. Work stress in the etiology of coronary heart disease a meta-analysis. Scand J Work Environ Health. 2006; 32(6):431-42.

45. Epel ES. Psychological and metabolic stress: A recipe for accelerated cellular aging? Hormones. 2009; 8(1):7-22.

46. Young SN, Smith SE, Pihl RO, Ervin FR. Tryptophan depletion causes a rapid lowering of mood in normal males. Psychopharmacology (Berl). 1985; 87(2):173-7.

47. McKittrick CR, Magariños AM, Blanchard DC, Blanchard RJ, McEwen BS, Sakai RR. Chronic social stress reduces dendritic arbors in CA3 of hippocampus and decreases binding to serotonin transporter sites. Synapse. 2000 May; 36(2):85-94.

48. Katsuyama H, Tomita M, Hidaka K, Fushimi S, Okuyama $\mathrm{T}$, Watanabe $\mathrm{Y}$, et al. Association between serotonin transporter gene polymorphisms and depressed mood caused by job stress in Japanese workers. Int J Mol Med. 2008 Apr; 21(4):499-505.

49. Karg K, Burmeister M, Shedden K, Sen S. The Serotonin Transporter Promoter Variant (5-HTTLPR), stress, and depression meta-analysis revisited evidence of genetic moderation. Arch Gen Psychiatry. 2011; 68(5):44-54. doi: 10.1001/archgenpsychiatry.2010.189.

50. Serebruany VL, Glassman AH, Malinin AI, Nomerov CB, Musselman DL, van Zyl LT et al. Platelet/endothelial biomarkers in depressed patients treated with the selective serotonin reuptake inhibitor sertraline after acute coronary events. Circulation. 2003; 108(8): 939-44.

51. Field T, Hernandez-Reif M, Diego M, Scanberg S, Kuhn C. Cortisol decreases and serotonin and dopamine increase following massage therapy. Int J Neurosci. 2005; 115(10):1397-413.

52. Chaouloff F. Serotonin, stress and corticoids. J Psychopharmacol. 2000; 14(2):139-51. 